CLINICAL STUDY

\title{
Selenium and goiter prevalence in borderline iodine sufficiency
}

\author{
Volker F H Brauer, Ulrich Schweizer ${ }^{1}$, Josef Köhrle ${ }^{1}$ and Ralf Paschke \\ Third Department of Medicine, University of Leipzig, Ph-Rosenthal-Street, 27, 04103 Leipzig, Germany and ${ }^{1}$ Institute for Experimental Endocrinology, \\ Charité Universitätsmedizin Berlin, Berlin, Germany
}

(Correspondence should be addressed to R Paschke; Email: ralf.paschke@medizin.uni-leipzig.de)

\begin{abstract}
Design: Selenium (Se) is required for the biosynthesis of selenocysteine-containing proteins. Several selenoenzymes, e.g. glutathione peroxidases and thioredoxin reductases, are expressed in the thyroid. Selenoenzymes of the deiodinase family regulate the levels of thyroid hormones. For clinical investigators, it is difficult to determine the role of Se in the etiology of (nodular-)goiter, because there are considerable variations of Se concentrations in different populations as reflected by dietary habits, bioavailability of Se compounds, and racial differences. Moreover, most previous clinical trials which investigated the influence of Se on thyroid volume harbored a bias due to the coexistence of severe iodine deficiency in the study populations.

Methods: Therefore, we investigated the influence of Se on thyroid volume in an area with borderline iodine sufficiency. First, we investigated randomly selected probands for urinary iodine (UI) and creatinine excretion in spot urine samples and determined the prevalence of goiter and thyroid nodules by high-resolution ultrasonography. After this, we determined urinary Se excretion (USe) in probands with goiter as well as in matched probands without goiter. Adjustments between the two compared groups were made for age, gender, history of thyroid disorders, smoking, and UI excretion.

Results: The mean USe and UI rates of all 172 probands were $24 \mu \mathrm{g} \mathrm{Se} / \mathrm{l}$ or $27 \mu \mathrm{g} \mathrm{Se} / \mathrm{g}$ creatinine and $96 \mu \mathrm{g} \mathrm{I} / \mathrm{l}$ or $113 \mu \mathrm{g} \mathrm{I} / \mathrm{g}$ creatinine indicating borderline selenium (20-200 $\mu \mathrm{g} / \mathrm{l})$ and iodine (100$200 \mu \mathrm{g} / \mathrm{l})$ sufficiency of the study population. Probands with goiter $(n=89)$ showed significantly higher USe levels than probands with normal thyroid volume $(n=83 ; P<0.05)$. USe rates were not influenced by present smoking or pregnancy.

Conclusions: In our investigation, USe was not an independent risk factor for the development of goiter. The higher USe in probands with goiter in comparison with probands with normal thyroid volume is most likely a coincidence. Se does not significantly influence thyroid volume in borderline iodine sufficiency because the iodine status is most likely the more important determinant.
\end{abstract}

European Journal of Endocrinology 155 807-812

\section{Introduction}

Selenium (Se) is an essential micronutrient and as a component of selenocysteine, Se is involved in the catalysis of all known selenoenzymes e.g., iodothyronine deiodinases. The iodothyronine deiodinases are required for the activation and the inactivation of the thyroid hormones T4 and T3 respectively (1-5). Since the human thyroid contains the highest concentration of Se in comparison with all other organs (3) even in the case of Se-deficient nutrition (6), an important role of Se for thyroid function was suggested. For clinical investigators, it is difficult to determine the role of Se in the etiology of (nodular-)goiter, because there are considerable variations of Se concentrations in different populations as reflected by dietary habits, bioavailability of Se compounds, and racial differences (4, 7-12). Moreover, previous clinical trials investigated populations with concurrent moderate to severe Se and iodine deficiency $(7,10,13,14)$ or failed to describe the iodine status of the investigated population (15). For these reasons, heterogeneous results with no differences for thyroid volume and Se concentration have been described for 140 males with goiter in comparison with 140 healthy probands (10), whereas other investigators (7) found a significantly negative relationship between thyroid volume and Se concentration in 73 school children. Many previous clinical trials $(7,10,13,16)$ which investigated the influence of Se on thyroid volume harbored a bias due to the coexistence of severe iodine deficiency in their study populations. Since the iodine status is likely to be the key factor in the maintenance of normal thyroid volume and function (17-20), trials in severely iodine-deficient areas could not clearly evaluate the role of Se deficiency in the etiology of goiter. Clinical investigators suggested that a coexistent Se deficiency increases thyroid-stimulating hormone (TSH) levels in severely iodine-deficient areas thereby subsequently contributing to the development of goiter $(13,16)$. Up to now, there is only sparse data 
about the influence of Se on thyroid volume in mildly iodine-deficient areas. Derumeaux et al. (21) found an inverse association between Se status and thyroid volume in women in France. Their study design (21) included assessment of biological specimen at inclusion but thyroid ultrasonography 1 year later. Middle Europe is an area of only borderline Se and iodine deficiency (9, 17-20, 22-24). In contrast to the previous studies which investigated how the Se status modifies the effects of severe iodine deficiency on thyroid volume, we set out to investigate how the Se status of probands with mild iodine deficiency/borderline iodine sufficiency influences thyroid volume. The design of our prospective clinical trial also aimed to investigate the role of Se as an independent factor in the etiology of (nodular-)goiter.

\section{Materials and methods}

We conducted a prospective clinical trial in 2002. The study protocol was approved by the local ethics committee. Eight hundred and five randomly selected students and employees of the University of Leipzig participated in the study. The probands were contacted by posters, university press, and the university intranet website. All participants lived in the area of Leipzig, Saxony and all volunteers were German. Probands were asked to give a spot urine sample and to fill in a questionnaire. All probands gave written informed consent.

First, we investigated randomly selected probands $(n=$ 805 ) for urinary iodine (UI) and creatinine excretion and determined the prevalence of goiter and thyroid nodules by high-resolution ultrasonography at the time of inclusion (17). After this, we determined urinary Se excretion (USe) in a subsample of probands with (nodular-)goiter $(n=89)$ as well as for matched probands without goiter $(n=89)$. Only a setting which eliminates other goitrogenic factors is able to investigate $\mathrm{Se}$ as an independent risk factor for goiter. Therefore, adjustments were done for age, gender, history of thyroid disorders, smoking, and UI excretion between the compared groups by a matching procedure. Iodine concentration was measured manually according to the protocol described by Sandell \& Kolthoff, which is based on the catalytic role of iodine in the reduction of ceric ammonium sulfate in the presence of arsenious acid (25, 26). Creatinine was measured as described by Jaffe (27).

Urinary Se concentration was determined by a spectrofluorimetric assay after oxidative digestion of the sample, subsequent reduction to Se-IV, and formation of piazselenol complexes using the 2,3diaminonaphtalene reagent (28). A commercially available standard serum and a standard urine (Sero AS, Billingstad, Norway) were used to verify the method, which has a detection limit of $7.5 \mu \mathrm{g} \mathrm{Se} / \mathrm{l}$ urine. The coefficient of variation in the Se range of human urine was below $21 \%$. Recovery of added Se in the form of selenite was between 88 and $112 \%$. The total recovery of absorbed selenate and selenite in the urine is about $95 \%(12)$.

Selenium and iodine excretions were correlated with creatinine excretion in every spot urine sample to minimize bias through kidney function and variable 24-h urinary volume as previously recommended $(29,30)$.

Thyroid volume determination was performed using a high-resolution real-time instrument (7.5 MHz). Thyroid volumes were calculated according to the spherical ellipsoid formula: volume $=\pi / 6 \times$ anteroposterior diameter $(\mathrm{cm}) \times$ width $(\mathrm{cm}) \times$ length $(\mathrm{cm})(31,32)$. Thyroid volumes $>18 \mathrm{ml}$ were considered to be enlarged in adult women and thyroid volumes $>25 \mathrm{ml}$ were considered to be enlarged in adult men, which corresponds to the mean \pm 3 s.D. in iodine-sufficient populations (33) and guaranteed, that gender-specific values for goiter are above the 97 th percentile of thyroid volumes found in iodine-replete control population (34). Hypo echoic thyroid glands detected by ultrasound, thus suggesting thyroid autoimmunity, were excluded from the further statistical evaluation.

Statistical analyzes were performed using SPSS software, version 10.0 (SPSS GmbH Software, Munich, Germany). Multivariable comparison between the groups was performed with ANOVA (endpoint USe). A value of $P<0.05$ was considered statistically significant.

Six urine samples of probands with normal thyroid volume were excluded from further statistical analysis due to partial evaporation during oxidation with nitric acid and 34 probands failed to give an answer about their smoking behavior.

\section{Results}

We investigated USe in the overall study population, in the two groups with and without goiters, and in females and males separately due to the possible influence of sex on USe $(19,21,35)$.The mean Se and iodine excretion rates of all 172 individuals were $24 \mu \mathrm{g} \mathrm{Se} / \mathrm{l}$ or $27 \mu \mathrm{g} \mathrm{Se} /$ g creatinine and $96 \mu \mathrm{g} \mathrm{I} / \mathrm{l}$ or $113 \mu \mathrm{g} \mathrm{I} / \mathrm{g}$ creatinine indicating borderline selenium $(20-200 \mu \mathrm{g} / \mathrm{l},(36))$ and iodine (100-200 $\mu \mathrm{g} / \mathrm{l}$, (34)) sufficiency of the study population. There was a slightly positive correlation between USe ( $\mu \mathrm{g}$ Se/g creatinine) and thyroid volume in females (Pearson correlation coefficient 0.196 significant at the 0.05 level ( $t$-test, two-tailed)), whereas we found a negative correlation between USe ( $\mu \mathrm{g} \mathrm{Se} / \mathrm{g}$ creatinine) and thyroid volume in males (Pearson correlation coefficient -0.297 significant at the 0.05 level ( $t$-test, two-tailed)). Probands with goiter $(0+q)$ showed significantly higher USe levels than probands with normal thyroid volume due to the higher USe rates in females ( $88 \%$ of the study population) with goiter (Table 1$)$. Males with goiter $(n=11)$ had lower USe than males with normal thyroid volume $(n=10)$ without reaching statistical significance $(P=0.124$, $t$-test, 
Table 1 Urinary selenium and I excretions of the study population.

\begin{tabular}{|c|c|c|c|}
\hline & $\begin{array}{c}\text { Urinary selenium excretion }{ }^{\mathrm{a}} \\
(\mu \mathrm{g} \text { Se/g creatinine })\end{array}$ & $\begin{array}{l}\text { Urinary iodine excretion }{ }^{\mathrm{a}} \\
(\mu \mathrm{g} \mathrm{l} / \mathrm{g} \text { creatinine })\end{array}$ & $\begin{array}{l}\text { Thyroid volume }{ }^{a} \\
(\mathrm{ml})\end{array}$ \\
\hline Normal thyroid volume $(n=83)$ & $23 \pm 12^{*}$ & $118 \pm 87$ & $10 \pm 3$ \\
\hline Goiter $(n=89)$ & $32 \pm 28^{*}$ & $108 \pm 75$ & $29 \pm 12$ \\
\hline Males with goiter $(n=11)$ & $18 \pm 3$ & $77 \pm 19$ & $45 \pm 18$ \\
\hline Females with goiter $(n=78)$ & $34 \pm 29^{\dagger}$ & $112 \pm 79$ & $26 \pm 9$ \\
\hline Males with normal thyroid volume $(n=10)$ & $22 \pm 8$ & $84 \pm 27$ & $13 \pm 3$ \\
\hline Females with normal thyroid volume $(n=73)$ & $23 \pm 12^{\dagger}$ & $122 \pm 96$ & $10 \pm 3$ \\
\hline Present smoker ( $n=30)$ ( $87 \%$ females) & $31 \pm 27$ & $110 \pm 73$ & $24 \pm 12$ \\
\hline Nonsmoker $(n=108)(87 \%$ females $)$ & $26 \pm 17$ & $111 \pm 84$ & $18 \pm 13$ \\
\hline
\end{tabular}

Selenium and iodine excretions were expressed as creatinine ratios in every spot urine sample to minimize bias through kidney function and variable $24-\mathrm{h}$ urinary volume. Symbols ( ${ }^{*}$ vs ${ }^{*}, \dagger$ vs $\dagger$ ) mark the corresponding differences at the significance level $P<0.05$ level, $(t$-test, two-tailed).

${ }^{\mathrm{a}}$ Mean \pm S.D.

two-tailed; Table 1). We found no differences in USe $(P>$ $0.05, t$-test, two-tailed) between smokers and nonsmokers or pregnant females $(n=9)$ versus no pregnancy. There was no correlation between USe and age. Females showed higher UI $(P<0.05$, $t$-test, two-tailed $)$ than males (Table 1$)$. The mean age of our probands $(n=$ 172) was $43 \pm 11$ years.

Figure 1 represents the normal distribution of USe of the study population.

We additionally compared the selenium excretion of the two groups (goiter yes versus goiter no) by ANOVA. Covariates are sex and age. UI excretion, history of thyroid disorders, and smoking behavior were not different between the compared groups at baseline in our initial matching procedure.

ANOVA revealed a significant dependence of USe on the presence of goiter (two compared groups: goiter yes versus goiter no). Multivariate $(P=0.012)$ as well as

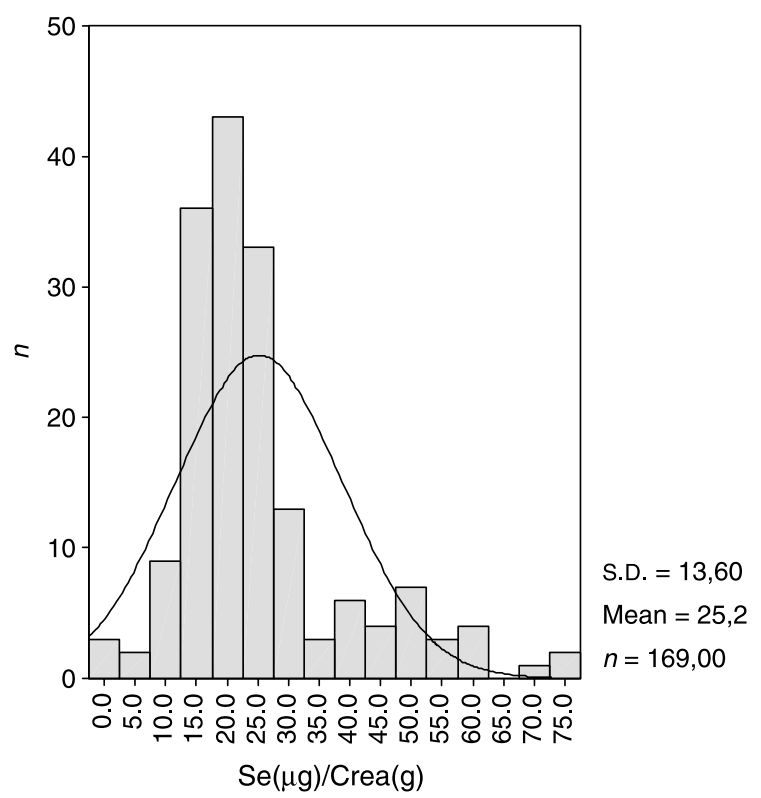

Figure 1 The $X$-axis represents the Se excretion $(\mu \mathrm{g} / \mathrm{g})$ and the $Y$-axis represents the total number of probands. Three specimen with higher excretion Se rates (132-188 $\mu \mathrm{g} \mathrm{Se/g}$ creatinine) were excluded for scale reasons. univariate $(P=0.04)$ tests showed significantly higher selenium levels in probands with goiter. This was also the case for the $t$-tests (Table 1 ).

Moreover, we investigated (ANOVA) a correlation between thyroid volume and selenium excretion to evaluate the possibility to predict thyroid volume by selenium excretion of individuals of our study population.

To avoid statistical bias by analyzing correlation between Use and thyroid volume in the highly preselected matching group, we described below dependence of USe from thyroid volume of the individuals of our study population especially in the unselected group of probands with goiter $(n=89)$.

ANOVA failed in multivariate $(P=0.28)$ as well as univariate $(P=0.28)$ tests to describe a dependence of USe from thyroid volume of the individuals of our overall study population, especially in the unselected group of probands with goiter, $P \geq 0.46$ (multivariate as well as univariate tests).

In conclusion, there were significant differences for USe between the compared groups: goiter versus no goiter. However, there was no possibility to predict thyroid volume by selenium excretion in individuals of our overall study population as also shown by the contrary interclass (male vs female) Pearson correlation coefficients.

\section{Discussion and conclusions}

In our population, USe was not an independent risk factor for the development of goiter (Fig. 1, Table 1). The most likely explanation for this finding is that our probands with goiter showed borderline iodine and selenium sufficiency. Concurrent Se and iodine deficiency lead to increases in thyroid volume and/or thyrotropin $(7,10,13,14,37)$. Combined severe deficiency of selenium and iodine can result in a more significant rise of TSH and thereafter increased thyroid gland weight/volume than produced by isolated iodine deficiency as demonstrated in rats (38). Moreover, severe selenium deficiency decreases the glutathione peroxidase enzyme and increases free radicals in the thyroid 
(3, 4, 15, 39). Most likely, Se status modulates thyroid volume in severe iodine deficiency areas $(7,10,13,14)$ rather than acting as an independent risk factor for goiter in (borderline) iodine-sufficient areas especially if the selenium status is borderline sufficient. In severely iodine-deficient areas, the antioxidant defence system/ antioxidant status as reflected by the Se status of probands seems to be lower in subjects with goiter than in subjects without goiter $(13,14)$. In line with our findings, Ozata et al. (10) did not find a correlation between thyroid volume and selenium status (plasma) in a moderately iodine-deficient Turkish population with endemic goiter. However, there still exists some uncertainty regarding the exact definition of 'Se status'. Often used measurements of 'Se status' include serum Se, plasma glutathione peroxidase activity (GPx), erythrocyte GPx, hair or toenail Se and USe. However, the exact interrelationships have not been determined for all these parameters. Urinary and plasma Se concentrations are more likely to reflect the present Se bioavailability of the human body than hair or toenail Se content that rather represent an integral over a longer period $(11,21,36)$. Regarding Se supplementation, there are significant differences in bioavailability between selenate and selenomethionine. Selenomethionine showed a strong relationship between $24 \mathrm{~h}$ urine and plasma Se (11). A survey in France (21) found an inverse correlation between serum Se levels and thyroid volume in 1108 females. Mean serum Se level in these women was $1.1 \mathrm{~mol} / \mathrm{l}(\approx 87 \mathrm{~g} / \mathrm{l})$ and clearly higher than in our study population (Table 1). One possible explanation for these finding is that the mean age of the investigated French cohort ranged from 45 to 60 years and was higher than in our study group. This is an important age difference, since Se excretion increases with older age $(22,29)$, but also different dietary Se intake cannot be ruled out. A 24-h USe of $200 \mu \mathrm{g}$ is regarded as normal (36), but clearly depends on the dietary habits of the study population. The mean UI of the French population (81-98 g/l, (21)) was indicative for borderline adequate iodine nutrition as in our investigation. However, in the French study, thyroid volumes were determined 1 year after the measurement of selenium. Finally, goiter prevalence increases with increasing age (18). Therefore, different goiter prevalences in the French and in our study population are a further explanation for the different findings. The increased excretion of USe in probands with goiter (Table 1) was an unexpected finding in our study. The thyroid gland can accumulate Se even under conditions of dietary Se deficiency $(4,6$, $40,41)$. The specific mechanisms of selective Se retention are poorly understood (3), but recent evidence in selenium-deficient transgenic mice has demonstrated that the thyroid is to a large extent independent from circulating plasma Se levels (42). Possibly, Se uptake or retention is impaired in patients with goiter. For example, USe could increase in animals and humans lacking the Se transport protein selenoprotein $\mathrm{P}(\mathrm{SePP})$ and it has been reported that several conditions adversely impact on SePP production (43), possibly increasing urinary Se loss. Thus, it would be interesting to determine whether goiter or other thyroid conditions impact on circulating SePP levels. An alternative explanation could be that the higher USe in probands with goiter in comparison with probands with normal thyroid volume is a coincidence and that Se does not significantly influence thyroid volume in (borderline) iodine sufficiency. The iodine status is likely to be the key factor in the maintenance of normal thyroid volume and function. Iodine sufficiency can probably prevent the contributing effects of deficiencies for Se, or copper (10). Investigations in mildly iodine-deficient areas (UI $>95 \mathrm{mcg} / \mathrm{l}$ ) demonstrated high frequencies of thyroid disorders. Up to 30\% of probands harbored thyroid nodules and up to $15 \%$ showed goiter $(17,44)$. Even minor differences in the ambient iodine supply seem to be reflected in the prevalence of thyroid abnormalities. Knudsen et al. (45) found a difference in goiter prevalence with $15 \%$ in mild versus $22.6 \%$ in moderately deficient areas in Denmark. Also the nodule size is increased by moderate iodine deficiency (45). Our probands with goiter showed mild iodine deficiency or rather borderline iodine sufficiency. However, the exact level of iodine intake that produces the lowest prevalence of thyroid disorders has still to be determined $(17,20,44)$ and might show large interindividual variability. Some authors (46) found higher (plasma/hair-) Se levels in men than in women, whereas other investigators found no influence of gender on (plasma/tissue-) Se levels in humans (47). Therefore, the influence of sex on Se excretion needs further evaluation. Also, the influence of present smoking on Se levels is discussed controversially. Some authors (48) described lower Se levels in smokers than in nonsmokers, whereas most investigators failed to find any correlation between smoking and Se levels of probands $(29,47)$ as in our investigation. However, we cannot exclude an information bias due to the fact that 34 probands failed to give an answer about their smoking behavior.

In conclusion, Se did not significantly influence thyroid volume in borderline iodine sufficiency and borderline-sufficient USe was not an independent risk factor for the development of goiter. The higher USe in probands with goiter in comparison with probands with normal thyroid volume is most likely a coincidence. Therefore, the iodine status is most likely the more important determinant for thyroid volume. Under conditions of only borderline iodine deficiency, there is probably a marginal interplay between iodine and other goitrogenic factors (e.g., Se). However, it remains to be elucidated why moderate to severe Se deficiency was a risk factor for developing goiter in concurrently severely iodine-deficient areas in previous reports. Moreover, further research is needed to understand if there is a sexspecific Se excretion and how factors such as selenium interact with the genetic susceptibility to develop a goiter. 


\section{Acknowledgements}

This study was supported in part by 'Forum Schilddrüse e.V.', 60596 Frankfurt/Main, Germany. Moreover, the authors wish to thank S Kappler (Charité-Universitätsmedizin Berlin, Germany) and R Gehrisch (University of Leipzig, Germany) for their help.

\section{References}

1 Arthur JR, Nicol F \& Beckett GJ. Hepatic iodothyronine 5'-deiodinase. The role of selenium. Biochemical Journal 1990272 537-540.

2 Behne D, Kyriakopoulos A, Meinhold H \& Kohrle J. Identification of type I iodothyronine $5^{\prime}$-deiodinase as a selenoenzyme. Biochemical and Biophysical Research Communications 1990173 1143-1149.

3 Kohrle J. The trace element selenium and the thyroid gland. Biochimie 199981 527-533.

4 Kohrle J, Brigelius-Flohe R, Bock A, Gartner R, Meyer O \& Flohe L. Selenium in biology: facts and medical perspectives. Biological Chemistry 2000381 849-864.

5 Ursini F, Maiorino M, Brigelius-Flohe R, Aumann KD, Roveri A, Schomburg D \& Flohe L. Diversity of glutathione peroxidases. Methods in Enzymology 1995252 38-53.

6 Zimmermann MB \& Kohrle J. The impact of iron and selenium deficiencies on iodine and thyroid metabolism: biochemistry and relevance to public health. Thyroid 200212 867-878.

7 Aydin K, Kendirci M, Kurtoglu S, Karakucuk EI \& Kiris A. Iodine and selenium deficiency in school-children in an endemic goiter area in Turkey. Journal of Pediatric Endocrinology and Metabolism $2002151027-1031$.

8 Contempre B, Vanderpas J \& Dumont JE. Cretinism, thyroid hormones and selenium. Molecular and Cellular Endocrinology 1991 81 193-195.

9 Gartner R, Gasnier BC, Dietrich JW, Krebs B \& Angstwurm MW. Selenium supplementation in patients with autoimmune thyroiditis decreases thyroid peroxidase antibodies concentrations. Journal of Clinical Endocrinology and Metabolism 200287 1687-1691.

10 Ozata M, Salk M, Aydin A, Sayin S, Oktenli C, Beyhan Z, Isimer A \& Ozdemir IC. Iodine and zinc, but not selenium and copper, deficiency exists in a male Turkish population with endemic goiter. Biological Trace Element Research 199969 211-216.

11 Robinson MF, Thomson CD, Jenkinson CP, Luzhen G \& Whanger PD. Long-term supplementation with selenate and selenomethionine: urinary excretion by New Zealand women. British Journal of Nutrition 199777 551-563.

12 Thomson CD. Selenium speciation in human body fluids. Analyst $1998123827-831$.

13 Giray B, Hincal F, Tezic T, Okten A \& Gedik Y. Status of selenium and antioxidant enzymes of goitrous children is lower than healthy controls and nongoitrous children with high iodine deficiency. Biological Trace Element Research 200182 35-52.

14 Giray B \& Hincal F. DNA base damage, antioxidant enzyme activities and selenium status in highly iodine-deficient goitrous children. Free Radical Research 200236 55-62.

15 Samir M \& El Awady MY. Serum selenium levels in multinodular goitre. Clinical Otolaryngology 199823 512-514.

16 Zagrodzki P, Nicol F, Arthur JR \& Slowiaczek M. Selenoproteins in human thyroid tissues. BioFactors 200114 223-227.

17 Brauer VF, Brauer WH, Führer D \& Paschke R. Iodine nutrition, nodular thyroid disease and urinary iodine excretion in a German university study population. Thyroid $200515364-370$.

18 Hampel R, Kulberg T, Klein K, Jerichow JU, Pichmann EG, Clausen V \& Schmidt I. Goiter incidence in Germany is greater than previously suspected. Medizinische Klinik 199590 324-329.

19 Knudsen N, Laurberg P, Perrild H, Bulow I, Ovesen L \& Jorgensen T. Risk factors for goiter and thyroid nodules. Thyroid $200212879-888$.
20 Laurberg P, Bulow Pedersen I, Knudsen N, Ovesen L \& Andersen S. Environmental iodine intake affects the type of nonmalignant thyroid disease. Thyroid $200111457-469$.

21 Derumeaux H, Valeix P, Castetbon K, Bensimon M, BoutronRuault MC, Arnaud J \& Hercberg S. Association of selenium with thyroid volume and echostructure in 35- to 60-year-old French adults. European Journal of Endocrinology 2003148 309-315.

22 Brtkova A, Magalova T, Bederova A, Babinska K \& Bartekova S. Serum selenium levels in healthy Slovak children and adolescents. Biological Trace Element Research 199967 49-54.

23 Kvicala J, Zamrazil V \& Jiranek V. Characterization of selenium status of inhabitants in the region Usti nad Orlici, Czech Republic by INAA of blood serum and hair and fluorimetric analysis of urine. Biological Trace Element Research 1999 71-72 31-39.

24 Simeckova A, Zamrazil V, Cerovska J, Kvicala J \& Bilek R. Status of magnesium, selenium and iodine saturation in the population of seven regions in the Czech Republic. Central European Journal of Public Health 19997 176-181.

25 Lorenz-Wawschinek O, Tiran B, Eber O \& Langsteger W. Photometric determination of iodine in urine. Experimental and Clinical Endocrinology 1994102 57-58.

26 Sandell EB. Micro determination of iodine by a catalytic method. Mikrochemica Acta 19371 9-25.

27 Jaffe M. Über den Niederschlag, welchen Pikrinsäure in normalem Harn erzeugt und über eine neue Reaction des Kreatins. Zeitschrift Physiologische Chemie 188610 391-400.

28 Schomburg L, Schweizer U, Holtmann B, Flohe L, Sendtner M \& Kohrle J. Gene disruption discloses role of selenoprotein P in selenium delivery to target tissues. Biochemical Journal $2003 \mathbf{3 7 0} 397-402$.

29 Rodriguez Rodriguez EM, Sanz Alaejos MT \& Diaz Romero C. Urinary selenium status of healthy people. European Journal of Clinical Chemistry and Clinical Biochemistry 199533 127-133.

30 Zöllner H, Als C, Gerber H, Hampel R, Kirsch G \& Kramer A. Screening for iodine deficiency iodide concentration or creatinine quotient in random urine. GIT Laboratory Journal 20013 138-139.

31 Hegedus L, Perrild H, Poulsen LR, Andersen JR, Holm B, Schnohr P, Jensen G \& Hansen JM. The determination of thyroid volume by ultrasound and its relationship to body weight, age, and sex in normal subjects. Journal of Clinical Endocrinology and Metabolism 198356 260-263.

32 Knudsen N, Bols B, Bulow I, Jorgensen T, Perrild H, Ovesen L \& Laurberg P. Validation of ultrasonography of the thyroid gland for epidemiological purposes. Thyroid 19999 1069-1074.

33 Gutekunst R, Becker W, Hehrmann R, Olbricht T \& Pfannenstiel P. Ultrasonic diagnosis of the thyroid gland. Deutsche Medizinische Wochenschrift 1988113 1109-1112.

34 WHO \& ICCIDD. Assessment of the Iodine Deficiency Disorders and Monitoring their Elimination Geneva, World Health Organization, 2001 (document WHO/NHD/01.1).

35 Pedersen KM, Iversen E \& Laurberg P. Urinary iodine excretion and individual iodine supplementation among elderly subjects: a crosssectional investigation in the commune of Randers, Denmark. European Journal of Endocrinology 1995132 171-174.

36 Sanz Alaejos M \& Diaz Romero C. Urinary selenium concentrations. Clinical Chemistry 199339 2040-2052.

37 Beckett GJ, Peterson FE, Choudhury K, Rae PW, Nicol F, Wu PS, Toft AD, Smith AF \& Arthur JR. Inter-relationships between selenium and thyroid hormone metabolism in the rat and man. Journal of Trace Elements and Electrolytes in Health and Disease 1991 $5265-267$.

38 Contempre B, Dumont JE \& Denef J. The iodothyronine deiodinase and $5^{\prime}$-deiodination. Bailliere's Clinical Endocrinology and Metabolism 19948 285-304.

39 Arthur JR, Nicol F \& Beckett GJ. The role of selenium in thyroid hormone metabolism and effects of selenium deficiency on thyroid hormone and iodine metabolism. Biological Trace Element Research 199234 321-325.

40 Bermano G, Nicol F, Dyer JA, Sunde RA, Beckett GJ, Arthur JR \& Hesketh JE. Tissue specific regulation of selenoenzyme gene expression during selenium deficiency in rats. Biochemical Journal 1995311 713-717. 
41 Behne D, Hilmert H, Scheid S, Gessner H \& Elger W. Evidence for specific selenium target tissues and new biologically important selenoproteins. Biochimica et Biophysica Acta 1988 $96612-21$.

42 Schomburg L, Riese C, Michaelis M, Griebert E, Klein MO, Sapin R, Schweizer U \& Kohrle J. Synthesis and metabolism of thyroid hormones is preferentially maintained in seleniumdeficient transgenic mice. Endocrinology 2006147 1306-1313.

43 Dreher I, Schmutzler C, Jakob F \& Kohrle J. Expression of selenoproteins in various rat and human tissues and cell lines. Journal of Trace Elements in Medicine and Biology 199711 83-91.

44 Laurberg P, Nohr SB, Pedersen KM, Hreidarsson AB, Andersen S, Bulow Pedersen I, Knudsen N, Perrild H, Jorgensen T \& Ovesen L. Thyroid disorders in mild iodine deficiency. Thyroid $2000 \mathbf{1 0}$ 951-963.

45 Knudsen N, Bulow I, Jorgensen T, Laurberg P, Ovesen L \& Perrild H. Goitre prevalence and thyroid abnormalities at ultrasonography: a comparative epidemiological study in two regions with slightly different iodine status. Clinical Endocrinology (Oxf) 200053 479-485.

46 Lopes P, Santos M, Vicente L, Rodrigues M, Pavao M, Neve J \& Viegas-Crespo A. Trace element status ( $\mathrm{Se}, \mathrm{Cu}, \mathrm{Zn})$ in healthy Portuguese subjects of Lisbon population: a reference study. Biological Trace Element Research 2004101 1-17.

47 Sesana G, Baj A, Toffoletto F, Sega R \& Ghezzi L. Plasma selenium levels of the general population of an area in northern Italy. Science of the Total Environment $1992 \mathbf{1 2 0} 97-102$.

48 Bashar S \& Mitra A. Effect of smoking on vitamin A, vitamin E, and other trace elements in patients with cardiovascular disease in Bangladesh: a cross-sectional study. Nutrition Journal 20043 1-5.

Received 22 May 2006

Accepted 28 September 2006 